Supplement of Earth Syst. Sci. Data, 12, 847-867, 2020

https://doi.org/10.5194/essd-12-847-2020-supplement

(C) Author(s) 2020. This work is distributed under

the Creative Commons Attribution 4.0 License.

(c) (i)

ज Earth System

¿̛̃ Science

亏Data

Supplement of

\title{
Annual oil palm plantation maps in Malaysia and Indonesia from 2001 to
} 2016

Yidi Xu et al.

Correspondence to: Le Yu (leyu@tsinghua.edu.cn)

The copyright of individual parts of the supplement might differ from the CC BY 4.0 License. 


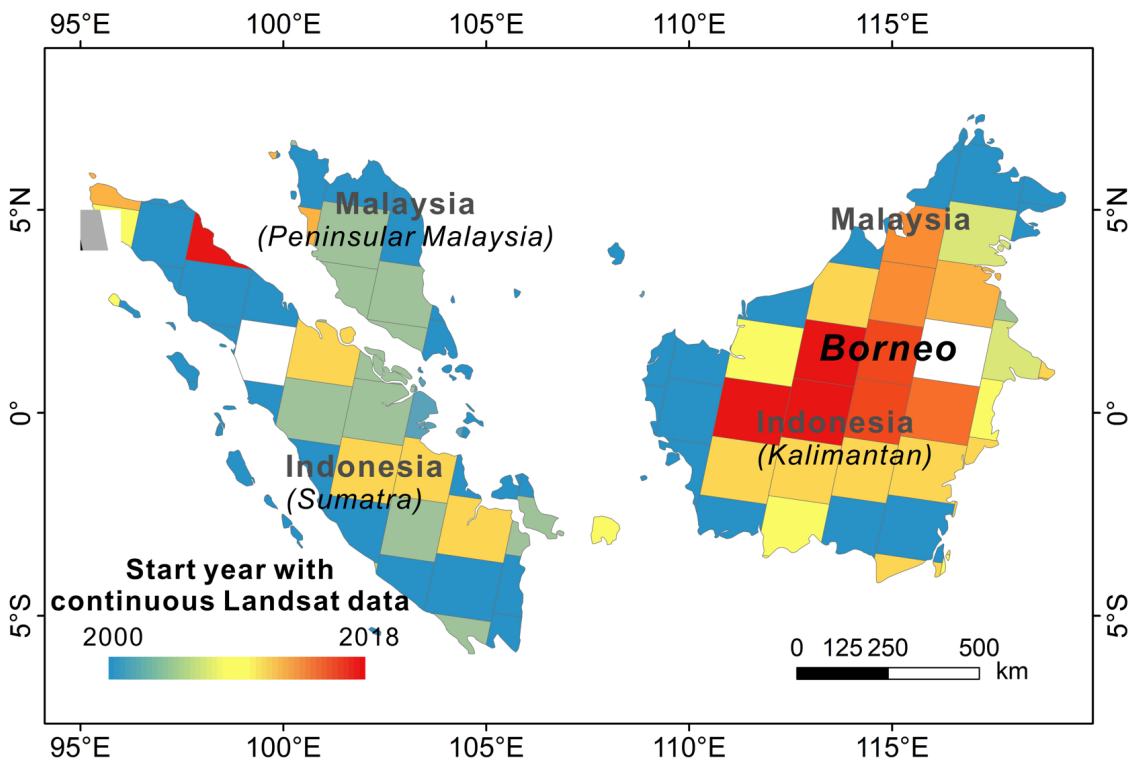

Figure S1: The Landsat data availability over 2000 to 2018. To fully cover the study area, 104 Landsat footprints are required. However, only $47.12 \%$ (49) of the total Landsat footprints meet the continuous data requirement for annual oil palm mapping (at least 1 scene available per year, cloud cover $<30 \%$ ), as indicated by blue color in this figure. 6.73\% (7) of the Landsat Path/Rows 5 even failed the continuous data requirement after 2015 (see the red color) (i.e., path/row: 117/59). 

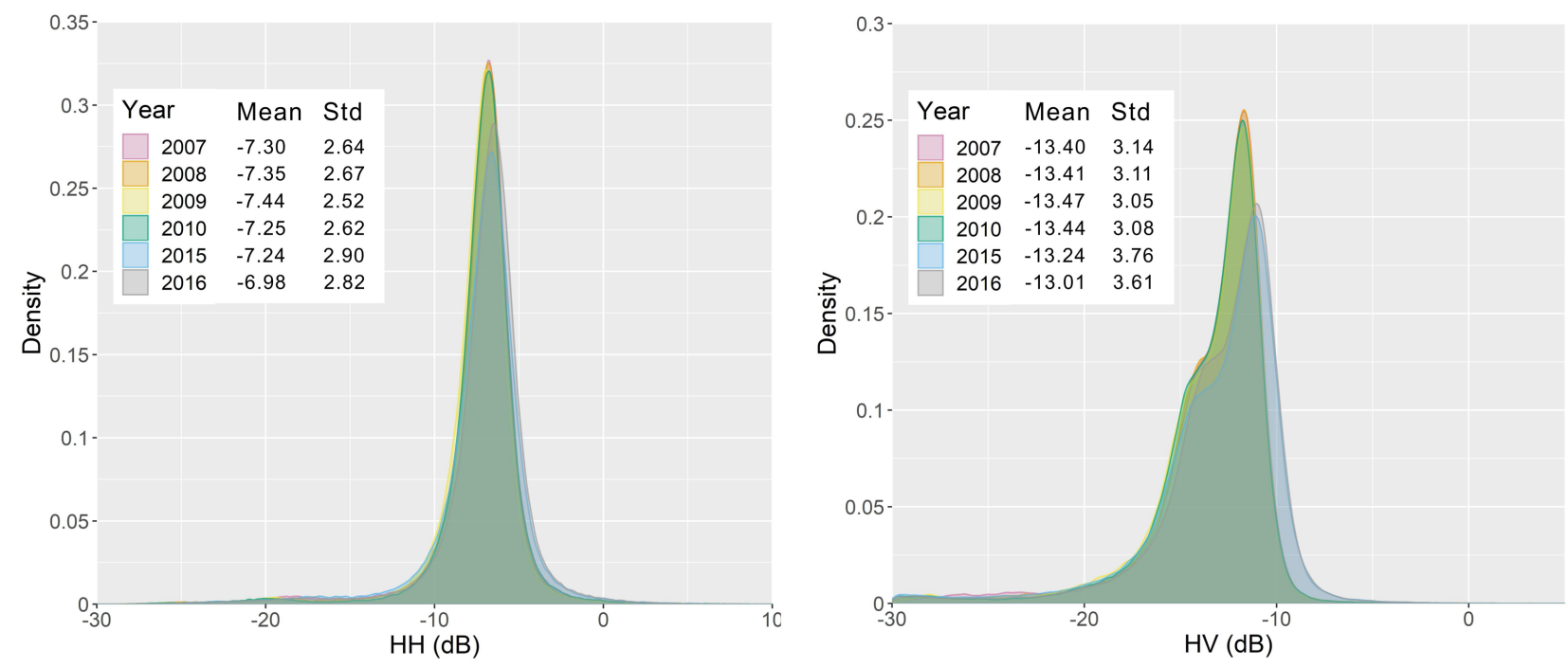

Figure S2. Density distribution of PALSAR/PALSAR-2 (a) HH (dB) and (b) HV (dB) in study area for 2007, 2008, 2009, 2010, 2015 10 and 2016 based on 250000 randomly generated points. The mean and standard deviation (std) value for the six years were given (mean: -7.44 -6.98 of $\mathrm{HH}$ and -13.47 -13.01 of $\mathrm{HV}$; std: 2.52 2.90 of $\mathrm{HH}$ and 3.05 3.76 of $\mathrm{HV}$ ). According to the result, the backscatter signals are relatively stable for the given period (2007-2010 and 2015-2016). 

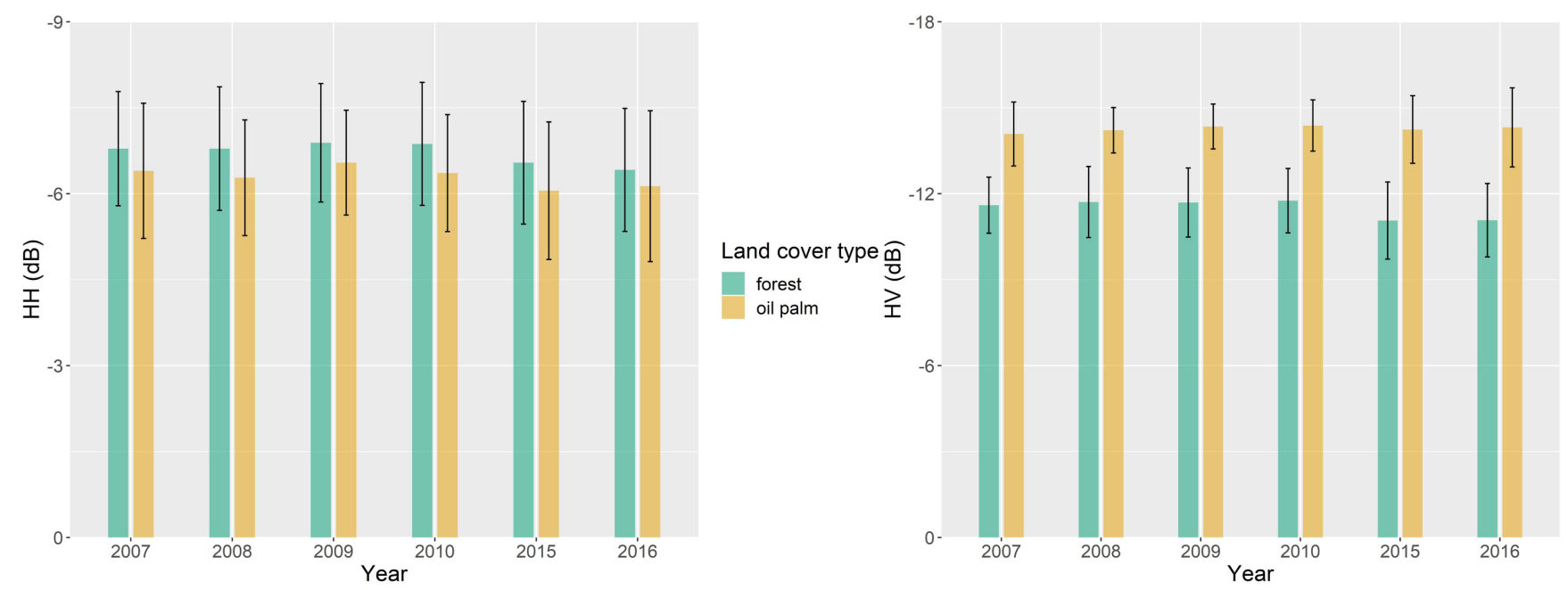

15 Figure S3. Comparison between PALSAR/PALSAR-2 (a) HH (dB) and (b) HV (dB) for forest and oil palm based on the training points. The HV (dB) for the forest and oil palm samples are differentiable during the given period (2007-2010 and 2015-2016). 
PALSAR images

Break detected results from MODIS

a)

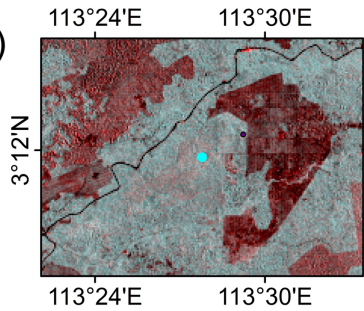

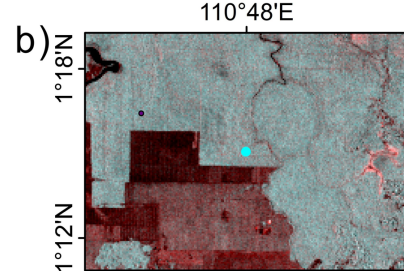

$110^{\circ} 48^{\prime} \mathrm{E}$

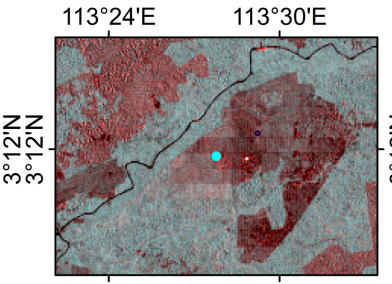

$113^{\circ} 24^{\prime} \mathrm{E}$

$113^{\circ} 30^{\prime} \mathrm{E}$

$113^{\circ} 24^{\prime} \mathrm{E} \quad 113^{\circ} 30^{\prime} \mathrm{E}$

$110^{\circ} 48^{\prime} \mathrm{E}$
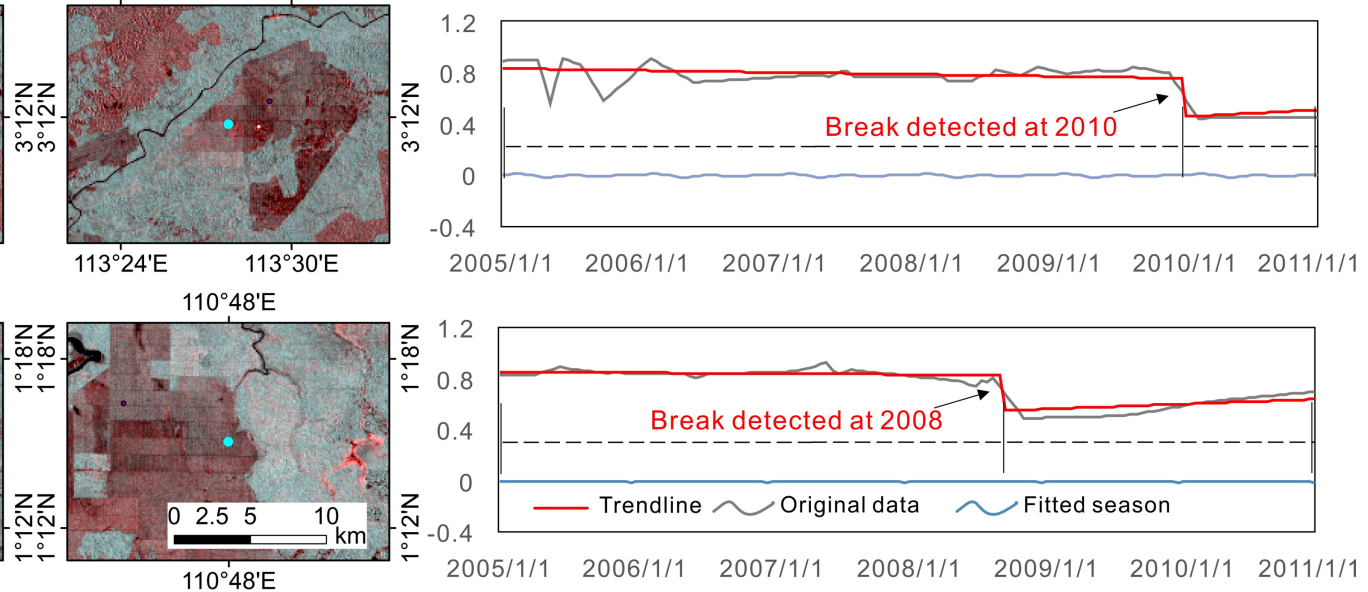

20 Figure S4: Two examples of the oil palm plantation change in PALSAR data (PALSAR/PALSAR-2 data downloaded from JAXA, http://www.eorc.jaxa.jp/ALOS/en/palsar_fnf/data/index.htm) and MODIS time series. The left graphs display the PALSAR-1 images before and after oil palm change (RGB: HH, HV, HV). In the right line figures, the original NDVI time series, fitted trend and seasonal components are shown. The detected break time in MODIS NDVI time-series is consistent with the time lapse of PALSAR data. 


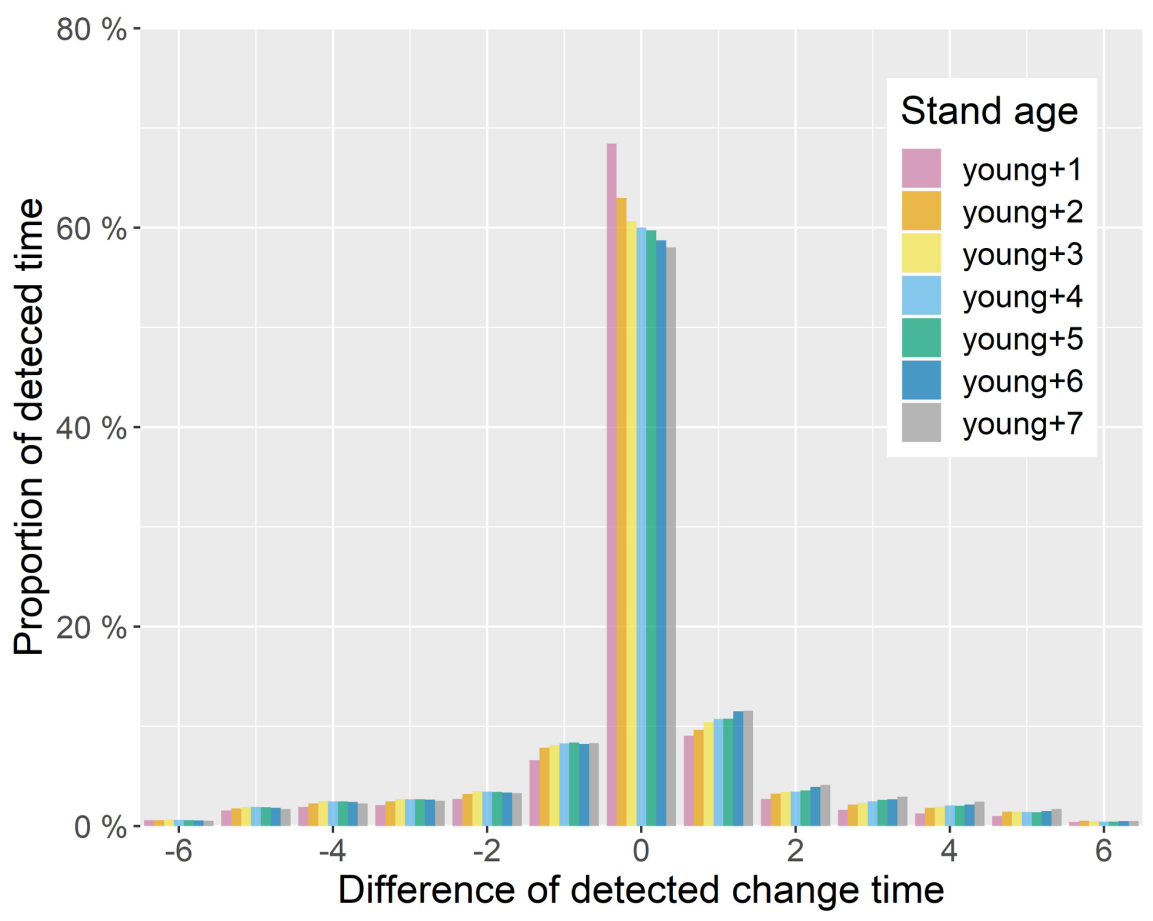

Figure S5. Effect of stand age. The values in $x$-axis is the difference between the detected change years using the replaced MODIS NDVI fragments (refer to older stand age) and the original NDVI curves (refer to young age). Negative values in $x$-axis refer to the detected change year using the older stand age is earlier than the original detected change year. 


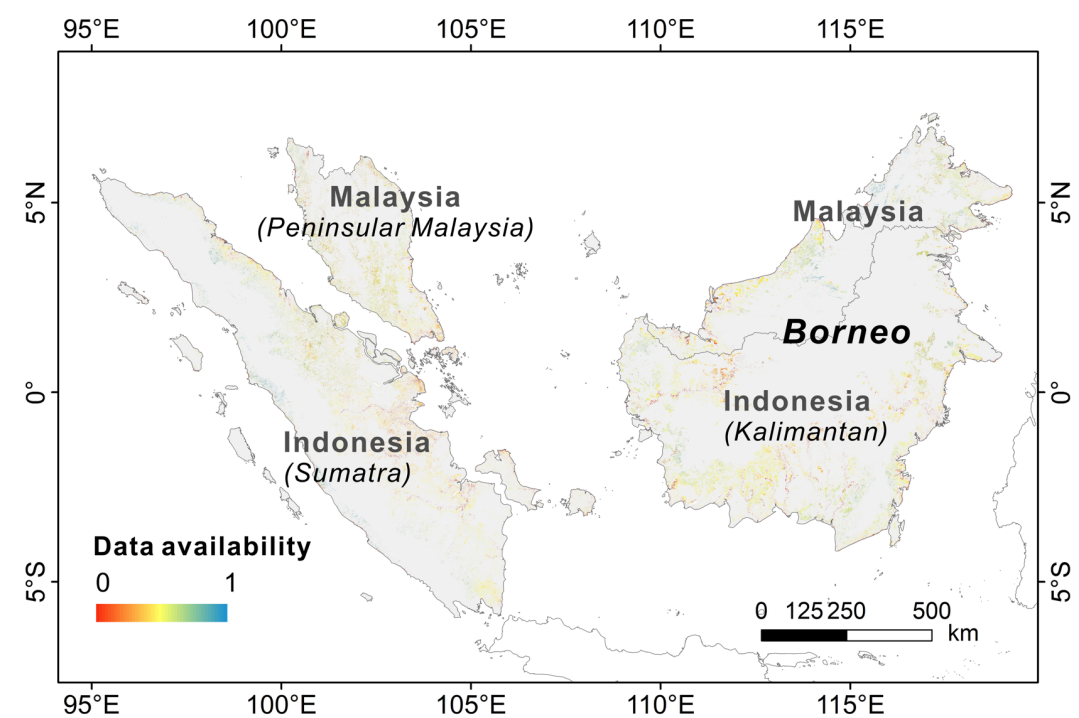

Figure S6: Data availability of the MODIS NDVI dataset from 2010 to 2015. The higher refers to the better data availability (more 35 data acquired during the 6 years) while the lower represents the poor data availability (data scarcity because of the cloud and data quality). 


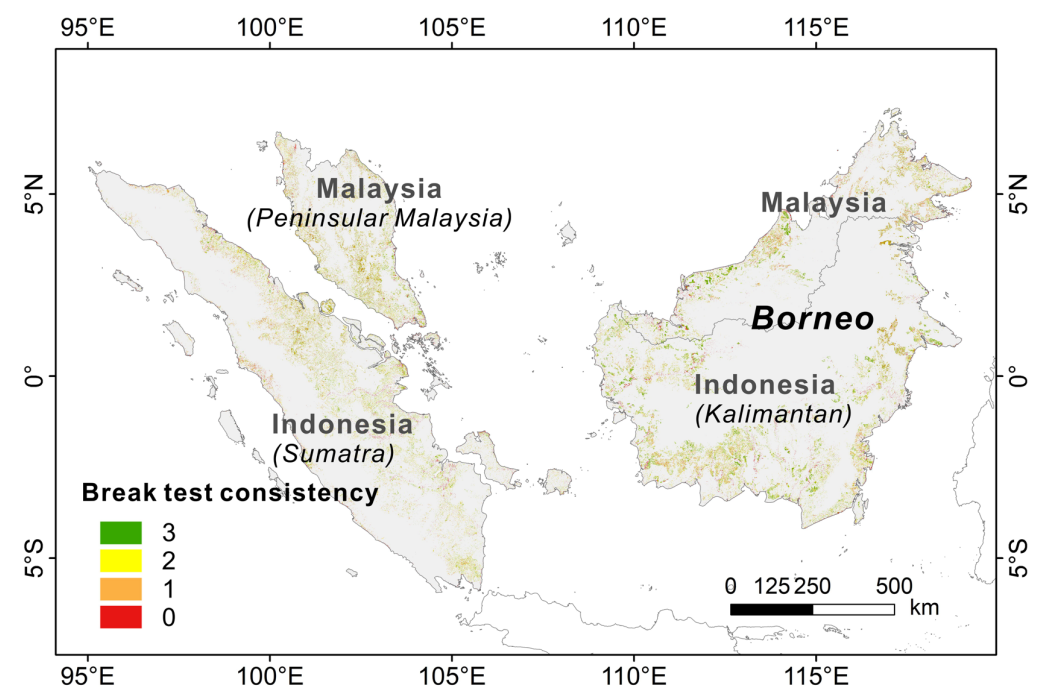

40 Figure S7: The quality of the oil palm dataset from 2011 to 2014. The numbers in the legend show how many breakpoint test methods detect the same change year during the whole period, e.g. 3 means that all the three breakpoint test methods detect the same change time during the period while the 0 means no break time detected in the whole period. 

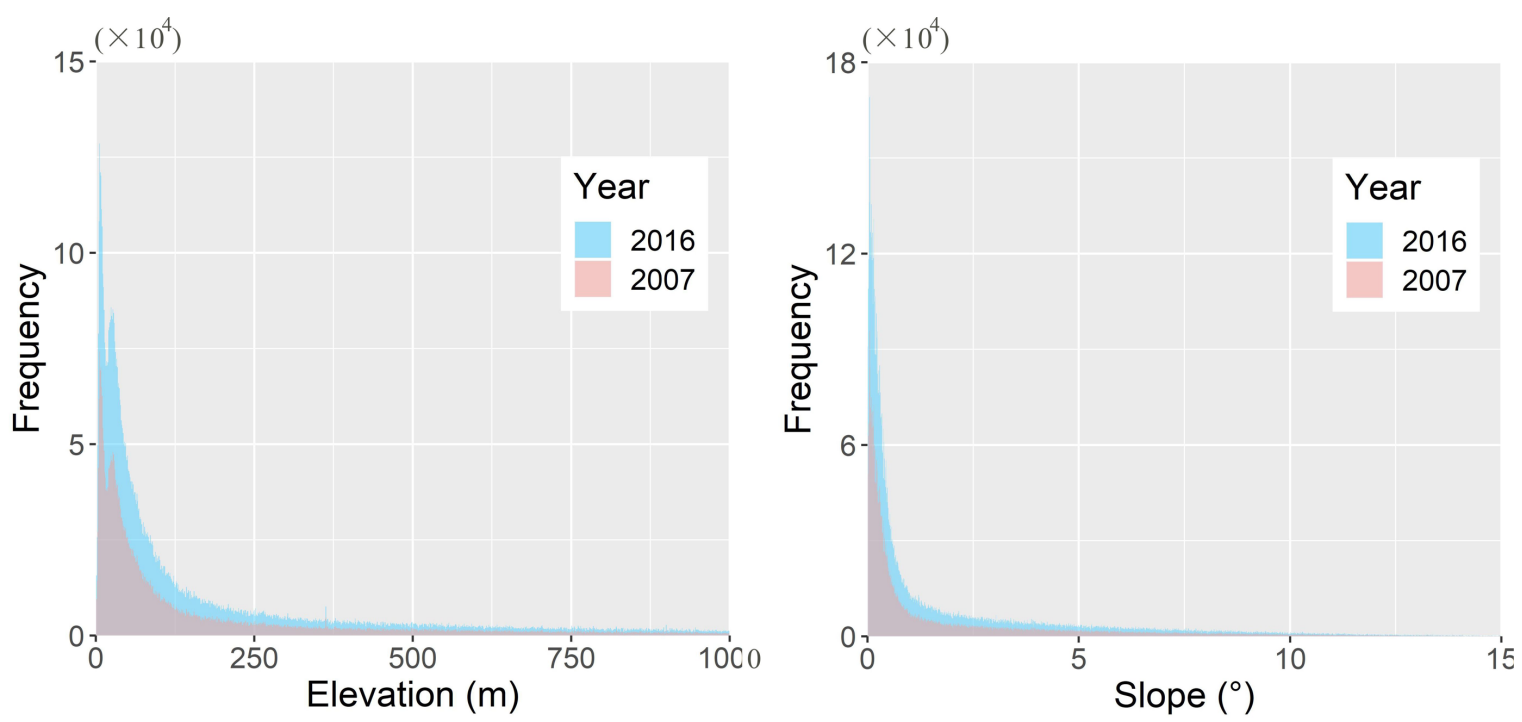

Figure S8: Frequency histograms of elevation and slope for oil palm distribution in 2007 and 2016 over the study area. According to the results, the oil palm is mainly distributed on the lowland areas (elevation $<250 \mathrm{~m}$, slope $<2.5$ degree). 


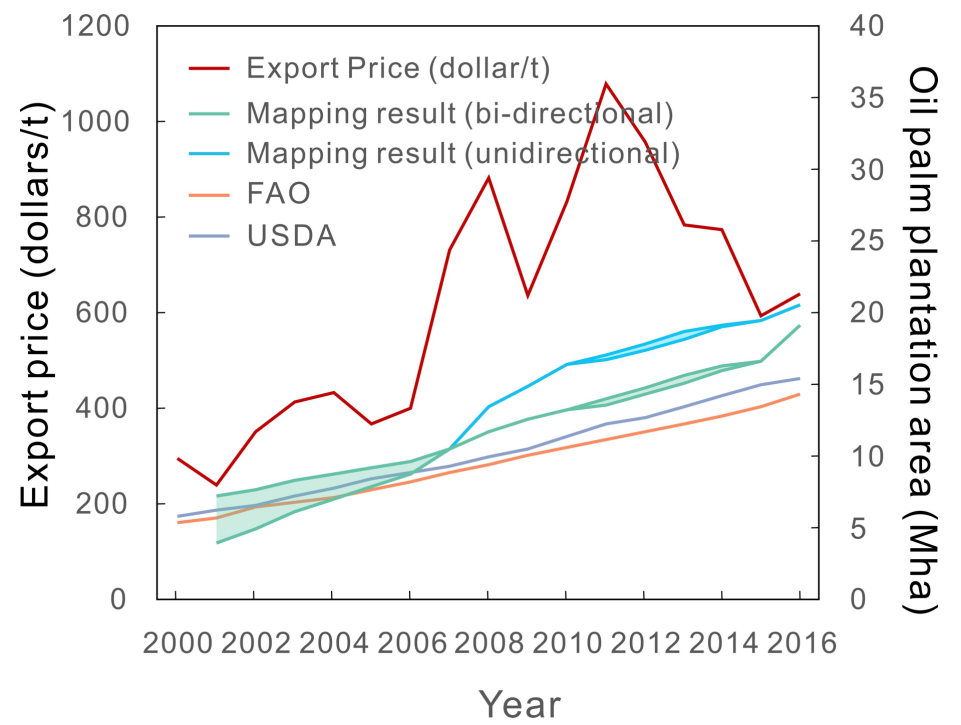

Figure S9: The comparison between oil palm plantation area and oil palm export price (total export value/export quantity in Malaysia and Indonesia, data source: FAOSTAT). 
55 Table S1: Oil palm increasing trends in different statistical datasets and our mapping results.

\begin{tabular}{|c|c|c|c|c|c|c|}
\hline & \multirow{3}{*}{ Period } & \multirow{3}{*}{ FAO } & \multirow{3}{*}{ USDA } & \multirow{3}{*}{$\begin{array}{c}\text { National statistics } \\
\text { (MPOB/BPS-Statistic) }\end{array}$} & \multicolumn{2}{|c|}{ Mapping results } \\
\hline & & & & & upper & lower \\
\hline & & & & & limit & limit \\
\hline \multirow{2}{*}{ Malaysia } & 2001-2016 & 0.108 & 0.123 & 1 & 0.203 & 0.265 \\
\hline & 2011-2015 & -0.067 & 0.137 & 0.160 & 0.164 & 0.147 \\
\hline \multirow{2}{*}{ Indonesia } & 2001-2016 & 0.460 & 0.520 & l & 0.573 & 0.674 \\
\hline & $2011-2015$ & 0.642 & 0.536 & 0.497 & 0.534 & 0.610 \\
\hline \multirow{2}{*}{ All } & 2001-2016 & 0.561 & 0.630 & / & 0.757 & 0.939 \\
\hline & 2011-2015 & 0.575 & 0.673 & 0.654 & 0.681 & 0.774 \\
\hline
\end{tabular}

